\title{
Pengaruh Waste dengan Pendekatan Lean Hospital Terhadap Pengendalian Biaya Kualitas dan Produksi
}

\section{Effect of Waste With Lean Hospital Approach Toward Quality and Production Cost Control}

\author{
Taufik Nugroho*, Nikma Fitriasari*, Putu Ayu Ekasari*, Ira Prasanti* \\ *Manajemen Rumah Sakit Fakultas Kedokteran Universitas Brawijaya \\ Email : vic_opiex@yahoo.co.id, nikma.fitriasari@gmail.com, kireiakai@gmail.com, \\ iraprasanti@yahoo.com, Kediri, Jawa Timur
}

\begin{abstract}
ABSTRAK
Instalasi farmasi beralih dari revenue center menjadi cost center terbesar rumah sakit berupa biaya produksi dan biaya kualitas. Identifikasi dan penghapusan waste diharapkan dapat menjadi solusi efisiensi biaya di rumah sakit. Tujuan penelitian untuk melihat pengaruh kejadian waste terhadap biaya produksi dan biaya kualitas. Penelitian menggunakan desain penelitian kuantitatif observasional dengan pendekatan cross sectional. Jumlah responden 33 dengan teknik total sampling. Analisis data menggunakan Partial Least Square (PLS). Hasil PLS menyatakan bahwa koefisien direct effect waste terhadap pengendalian biaya produksi sebesar 0.184 , berarti waste berpengaruh positif dan signifikan terhadap pengendalian biaya produksi. Koefisien direct effect pengendalian biaya kualitas terhadap pengendalian biaya produksi sebesar 0.616, berarti pengendalian biaya kualitas berpengaruh positif dan signifikan terhadap pengendalian biaya produksi. Koefisien indirect effect waste terhadap pengendalian biaya produksi melalui pengendalian biaya kualitas sebesar -0.056, berarti waste berpengaruh negatif dan tidak signifikan terhadap pengendalian biaya produksi melalui pengendalian biaya kualitas. Semakin tinggi waste, maka cenderung meningkatkan pengendalian biaya kualitas dan biaya produksi. Semakin baik pengendalian biaya kualitas yang disebabkan oleh semakin rendahnya waste, maka cenderung meningkatkan pengendalian biaya produksi, meskipun penurunan tersebut tidak signifikan.
\end{abstract}

Kata Kunci : Waste; Lean; Biaya Kualitas; Biaya Produksi.

\begin{abstract}
Pharmacy unit switches from revenue center to hospital cost center because of production and quality cost. Identifying and removing waste are expected to become solution of hospital cost efficiency. The purpose of this research is to find out the effect of waste toward quality cost and production cost control. This research used observational quantitative design with cross sectional approach. The amount of responden was 33 with total sampling technique. The data was analyzed using Partial Least Square (PLS). The result of PLS showed that the coefficient of direct effect waste toward the quality cost control was 0.184 , which means waste has positive and significant effect on quality cost control. The direct effect coeffient of the quality cost control toward production cost control was 0.616, which means the quality cost control has positive and significant effect on production cost control. The indirect effect coefficient of waste toward production cost control through quality cost control was -0.056, which means waste has negative and unsignificant effect on production cost control through quality cost control. If waste getting increased, it tends to increase production cost control and quality cost control. If the quality cost control getting better, that is caused by decreasing waste, the production cost control tend to increase, despite unsignificantly.
\end{abstract}

Keywords : Waste; Lean; Production Cost; Quality Cost. 


\section{PENDAHULUAN}

Pengendalian mutu dan biaya di setiap unit pelayanan rumah sakit sangat diperlukan dalam era Universal Health Coverage (Badan Penyelenggara Jaminan Sosial, 2016). Kendali biaya dilakukan dengan menjamin pembiayan yang dibebankan kepada pasien harus sesuai kebutuhan medis. Kendali biaya mutlak dilakukan di unit yang menjadi revenue center dan cost center rumah sakit seperti instalasi farmasi (Dea, Kurniasih, Subarnas, \& Djuhaeni, 2015). Kontribusi instalasi farmasi adalah sebesar 5060\% dari seluruh potensi finansial rumah sakit (Galistiani \& Satibi, 2013). Sekitar 80\% kunjungan pasien ke rumah sakit akan menghasilkan resep obat (Siregar \& Amalia, 2004). Kendali biaya di instalasi farmasi dapat meningkatkan keuntungan rumah sakit. Salah satu upaya pengendalian biaya adalah dengan pendekatan lean hospital.

Lean hospital merupakan sebuah upaya berkelanjutan dari rumah sakit untuk menghilangkan waste dan meningkatkan value produk pelayanan bagi pelanggan (Fourie \& Umeh, 2017). Waste didefinisikan sebagai penggunaan sumber daya yang tidak menambah value apapun pada produk (Sayyida, Fahma, \& Iftadi, 2018). Terdapat tujuh kelompok waste yang perlu diidentifikasi menggunakan lean tools yaitu over production, defects, unnecessary inventory, inappropriate processing, excessive transportation, waiting, dan unnecessary motion (Costa \& Filho, 2016; Green, Crawford, Bresnen, \& Rowe, 2015; Sigalingging, Tama, \& Riawati, 2014). Identifikasi waste akan menentukan metode yang diperlukan untuk melakukan penghilangan waste (Radnor, Holweg, \& Waring, 2012). Penghilangan waste di rumah sakit sangat kompleks karena melibatkan banyak regulasi dan kekuatan kelompok profesional (Hasle, Nielsen, \& Edwards, 2016). Sumber daya yang dihemat melalui penghilangan waste dapat meningkatkan profitabilitas melalui pengendalian biaya kualitas dan produksi (Sigalingging et al., 2014).

Pengendalian biaya kualitas adalah salah satu proses manajemen secara berkelanjutan berupa tindakan untuk mengarahkan aktifitas agar tidak menyimpang berkaitan dengan upaya mengubah produk bermutu buruk menjadi produk bermutu baik (Anik, 2013; Hapsari, Saputra, \& Rismadi, 2013; Horngren, Charles, Srikant, \& Foster, 2008). Biaya kualitas dapat dikategorikan menjadi biaya pencegahan (prevention cost), biaya penilaian (appraisal cost), biaya kegagalan internal (internal failure cost) dan biaya kegagalan eksternal (external failure cost) (Wahyuningtias, 2013). Biaya pencegahan dibutuhkan untuk menurunkan jumlah hasil produksi yang berkualitas buruk. Biaya penilaian dibutuhkan untuk mendeteksi produk yang tidak memenuhi spesifikasi. Biaya kegagalan internal terjadi pada suatu produk yang cacat sebelum dikirim ke pelanggan. 
Taufik Nugroho, Nikma Fitriasari, Putu Ayu Ekasari, Ira Prasanti : Effect of Waste With Lean ....

Biaya kegagalan eksternal dikeluarkan untuk memperbaiki kerusakan kualitas dan kehilangan peluang laba karena produk dikembalikan oleh pelanggan (Tandiontong, Sitanggang, \& Carolina, 2010). Peningkatan upaya pengendalian biaya kualitas berbanding lurus dengan efisiensi produksi (Hansen \& Mowen, 2009). Semakin buruk kualitas produk dapat mengakibatkan biaya kualitas semakin tinggi (Bawon, Sondakh, \& Mawikere, 2013). Pengendalian biaya kualitas yang lebih bijaksana dapat mengurangi pengendalian biaya produksi yang besar (Martusa, Haslim, \& Henri, 2011).

Pengendalian biaya produksi adalah proses manajemen secara berkelanjutan berupa tindakan untuk mengarahkan aktifitas agar tidak menyimpang berkaitan dengan aktivitas operasional dalam pembuatan barang dan penyediaan jasa (Anik, 2013; Hapsari et al., 2013). Biaya produksi terdiri dari prime cost dan biaya konversi. Prime cost terdiri dari biaya bahan baku dan biaya tenaga kerja langsung. Biaya bahan baku meliputi harga pokok semua bahan dasar pembuatan suatu jenis produk. Biaya tenaga kerja langsung meliputi biaya dalam bentuk upah yang diberikan kepada semua tenaga kerja yang secara langsung ikut serta dalam proses produksi. Biaya konversi terdiri dari seluruh biaya overheard termasuk biaya tenaga kerja tidak langsung. Biaya overhead merupakan semua biaya yang sulit untuk ditelusuri secara langsung dalam produk atau aktivitas produksi (Bawon et al., 2013; Hansen \& Mowen, 2009; Hapsari et al., 2013).

Penerapan lean hospital diharapkan dapat mengidentifikasi dan menghilangkan waste sehingga pengendalian biaya kualitas dan produksi di instalasi farmasi rumah sakit dapat berjalan dengan baik. Penelitian ini bertujuan melihat pengaruh waste dengan pendekatan lean hospital terhadap pengendalian biaya produksi dan biaya kualitas pada instalasi farmasi rumah sakit.

\section{METODE}

Desain penelitian bersifat kuantitatif observasional dengan pendekatan cross sectional di sebuah rumah sakit umum tipe $\mathrm{C}$ milik pemerintah daerah (The X Hospital). Pengambilan data dilakukan dengan teknik total sampling pada petugas instalasi farmasi. Instrumen penelitian berupa kuesioner tertutup dengan skala Likert yang dibagikan untuk dilengkapi secara mandiri oleh responden pada bulan Juli sampai Agustus 2018.

Variabel yang digunakan dalam penelitian adalah kejadian waste sebagai variabel bebas, serta pengendalian biaya kualitas dan pengendalian biaya produksi sebagai variabel tergantung. Hasil penelitian dianalisis dengan Partial Least Square (PLS). 


\section{HASIL}

Jumlah responden yang terlibat dalam penelitian adalah sebanyak 33 orang pegawai instalasi farmasi The $X$ Hospital. Karakteristik responden didapatkan bahwa sebagian besar responden berumur 25 - 35 tahun (45,5\%), berjenis kelamin perempuan (69,7\%), pegawai tidak tetap (75,8\%), sudah menikah (57,6\%), lulusan SLTA atau sarjana (39,4\%), menjabat sebagai staf (66,7\%), dan telah bekerja selama 1-5 tahun (57,6\%). Karakteristik responden cukup homogen karena diambil dalam lingkup satu unit pelayanan yang memiliki standar rekrutmen dan profesi yang jelas. Kemampuan responden dalam memahami pernyataan yang diajukan dalam instrumen penelitian diharapkan dapat didukung dari karakteristik umur yang telah dewasa, pendidikan cukup, menjabat sebagai staf walaupun beberapa masih berstatus pegawai tidak tetap, dan telah memiliki pengalaman kerja di unit farmasi.

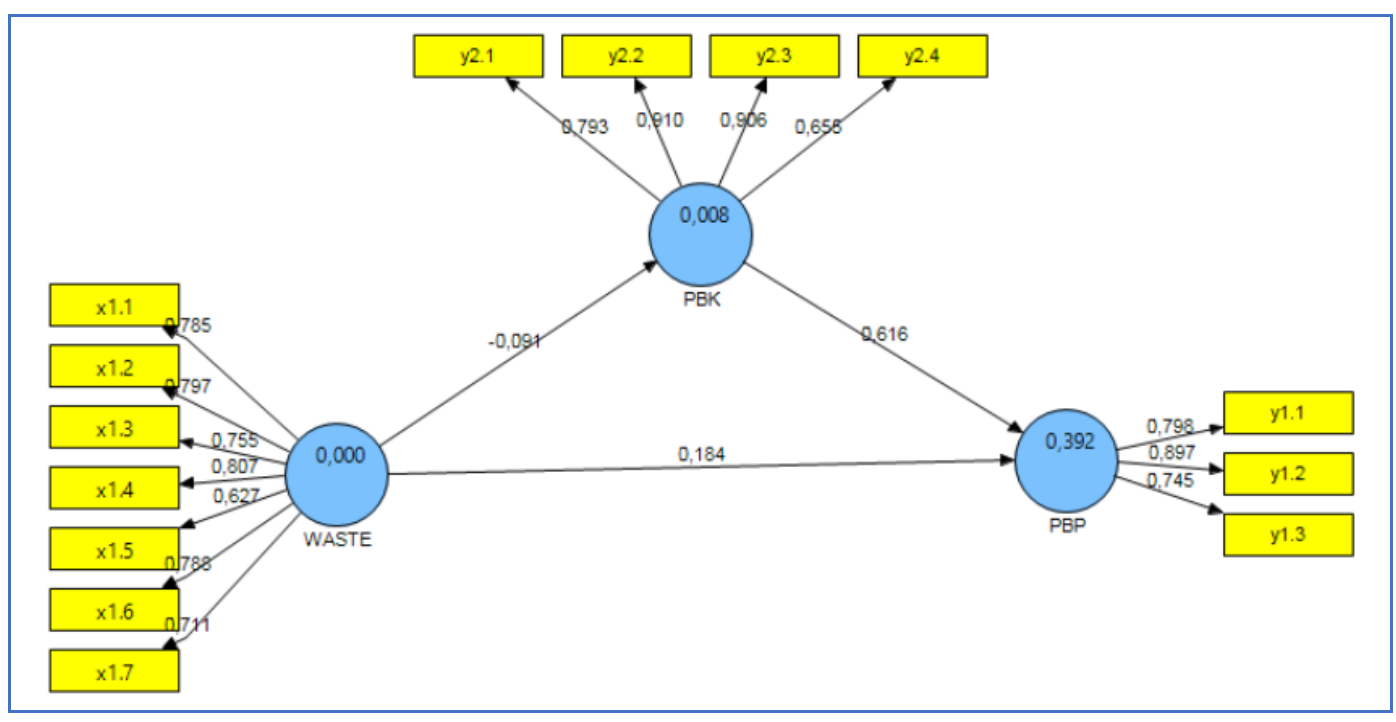

Gambar 1. Diagram PLS Penelitian

Hasil analisis PLS dapat menunjukkan nilai loading factor sebagai kontribusi indikator pengukur variabel, nilai goodness of fit sebagai relevansi teori, dan nilai signifikasi dari tiap-tiap variabel. Hasil analisis penelitian dijabarkan secara terperinci pada Gambar 1.

Model pengukuran menginformasikan bahwa dimensi inappropriate process (X1.4), pengendalian biaya penilaian (Y2.2), dan pengendalian biaya SDM (Y1.2) memiliki nilai loading paling besar, dengan nilai masing-masing 0,807, 0,910, dan 0,897. Hal ini menunjukkan bahwa ketiga dimensi tersebut merupakan dimensi yang paling 
Taufik Nugroho, Nikma Fitriasari, Putu Ayu Ekasari, Ira Prasanti : Effect of Waste With Lean ....

dominan dalam mengukur variabel latennya.

Hasil Goodness of fit Model menunjukkan nilai sebesar 39.7\%, artinya kontribusi waste terhadap pengendalian biaya kualitas dan pengendalian biaya produksi secara keseluruhan hanya sebesar 39,7\%. Sisanya sebesar 60.3\% merupakan kontribusi faktor lain yang tidak dibahas dalam penelitian ini.

Kriteria pengujian menyatakan bahwa apabila nilai $\mathrm{T}$ statistik $\geq \mathrm{T}$ tabel (1.96) maka dinyatakan ada pengaruh signifikan variabel eksogen terhadap variabel endogen. Hasil pengujian menyatakan kejadian waste berpengaruh negatif dan tidak signifikan terhadap pengendalian biaya kualitas (- 0,091), pengendalian biaya kualitas berpengaruh positif dan signifikan terhadap pengendalian biaya produksi $(0,616)$, kejadian waste berpengaruh positif dan signifikan terhadap pengendalian biaya produksi $(0,184)$, dan kejadian waste berpengaruh negatif dan tidak signifikan terhadap pengendalian biaya produksi melalui pengendalian biaya kualitas $(-0,056)$.

\section{PEMBAHASAN}

Model pengukuran menginformasikan bahwa dimensi inappropriate process (X1.4), pengendalian biaya penilaian (Y2.2), dan pengendalian biaya SDM (Y1.2) memiliki nilai loading paling besar. Dimensi inappropriate process menjadi pemborosan terbesar di Instalasi Farmasi. Hal ini sesuai dengan penelitian Sudradjat (2016) yang menyatakan bahwa pemborosan paling besar ditemukan pada inappropriate process dan waiting (Sudradjat, 2016). Dimensi pengendalian biaya penilaian menjadi dimensi paling dominan dalam pengendalian biaya kualitas karena penilaian merupakan cara yang paling sederhana dan mudah untuk diterapkan untuk mengetahui kualitas produksi (Hadi, 2003). Pengendalian biaya SDM menjadi kontribusi dominan dalam pengendalian biaya produksi karena beban biaya personel mencapai $47 \%$ dari keseluruhan biaya operasional (Suharyono \& Adisasmito, 2006).

Koefisien direct effect waste terhadap pengendalian biaya kualitas sebesar -0,091 menunjukkan bahwa waste berpengaruh negatif dan tidak signifikan terhadap pengendalian biaya kualitas. Pelanggan produksi jasa selalu menuntut untuk memperoleh pelayanan yang berkualitas tinggi. Pelayanan yang tidak berkualitas merupakan sebuah waste yang memerlukan biaya perbaikan. Hal ini mengakibatkan perlunya dilakukan upaya pengendalian biaya kualitas untuk menurunkan waste agar dapat meningkatkan keuntungan bagi perusahaan (Modi \& Thakkar, 2014). 
Koefisien direct effect pengendalian biaya kualitas terhadap pengendalian biaya produksi merupakan pengaruh yang paling dominan yaitu sebesar 0.616. Pengendalian biaya kualitas berpengaruh positif dan signifikan terhadap pengendalian biaya produksi. Hal ini disebabkan karena biaya kualitas merupakan bagian dari biaya produksi (13). Semakin baik pengendalian biaya kualitas maka cenderung meningkatkan pengendalian biaya produksi. Pengendalian biaya produksi merupakan hasil dan tujuan dari upaya pengendalian biaya kualitas. Upaya pengendalian biaya kualitas pada instalasi farmasi rumah sakit bertujuan untuk menghasilkan pelayanan bermutu sehingga pengendalian biaya produksi dapat optimal (Anik, 2013).

Koefisien direct effect waste terhadap pengendalian biaya produksi sebesar 0.184 menyatakan bahwa waste berpengaruh positif dan signifikan terhadap pengendalian biaya produksi. Hal ini berarti semakin tinggi waste maka cenderung meningkatkan pengendalian biaya produksi. Proses produksi dengan waste minimal dapat menurunkan biaya produksi. Proses produksi yang efisien dapat menurunkan biaya produksi yang akhirnya menghasilkan profit yang lebih besar bagi perusahaan. Efisiensi pada instalasi farmasi rumah sakit dilakukan dengan mengurangi biaya produksi melalui pengurangan waste dalam proses pelayanan, sehingga memberikan keuntungan bagi rumah sakit (Pujotomo \& Armanda, 2011).

Koefisien indirect effect waste terhadap pengendalian biaya produksi melalui pengendalian biaya kualitas sebesar - 0.056 menyatakan bahwa waste berpengaruh negatif dan tidak signifikan terhadap pengendalian biaya produksi melalui pengendalian biaya kualitas. Hasil ini sesuai dengan penelitian lain yang menunjukkan bahwa semakin baik pengendalian biaya kualitas yang disebabkan oleh semakin rendahnya waste maka cenderung dapat meningkatkan pengendalian biaya produksi meskipun tidak signifikan (Sigalingging et al., 2014).

Pengaruh waste terhadap pengendalian biaya kualitas terlalu kecil dibandingkan pengaruh faktor lain yang tidak dibahas dalam penelitian ini sehingga hasilnya tidak signifikan. Hal ini juga mempengaruhi signifikansi dan hasil indirect effect waste terhadap pengendalian biaya produksi apabila melibatkan pengendalian biaya kualitas dan hasil Goodness of fit Model sebesar 39.7\%. Beberapa faktor lain seperti profitabilitas, bauran produk, dan bauran pemasaran yang berpengaruh terhadap biaya kualitas dan biaya produksi dapat dipertimbangkan untuk diperhitungkan pada penelitian selanjutnya. 
Taufik Nugroho, Nikma Fitriasari, Putu Ayu Ekasari, Ira Prasanti : Effect of Waste With Lean ....

\section{SIMPULAN}

Identifikasi waste yang rendah menunjukkan bahwa pengendalian biaya kualitas sudah baik, sehingga pengendalian biaya produsi juga baik meskipun hasilnya tidak signifikan. Penelitian selanjutnya dapat menambahkan variabel lain yang diperkirakan lebih berpengaruh terhadap pengendalian biaya kualitas dan biaya produksi pada instalasi farmasi rumah sakit.

\section{UCAPAN TERIMA KASIH}

Ucapan terima kasih kami sampaikan kepada Program Studi Magister Manajemen Rumah Sakit Fakultas Kedokteran Universitas Brawijaya atas bimbingan dan dukungan kepada peneliti.

\section{DAFTAR PUSTAKA}

Anik, A. P. (2013). Evaluasi Penerapan Akuntansi Pertanggungjawaban sebagai Alat Pengendalian Biaya Produksi. Jurnal EMBA, 1(4), 1667-1676.

Badan Penyelenggara Jaminan Sosial. Peraturan Badan Penyelenggara Jaminan Sosial Kesehatan Nomor 8 Tahun 2016 (2016).

Bawon, D. N. P., Sondakh, J. J., \& Mawikere, L. (2013). Penerapan Biaya Kualitas untuk Meningkatkan Efisiensi Biaya Produksi pada PT. Pertani (Persero) Cabang Sulawesi Utara. Jurnal Riset Akuntansi Going Concern FEB UNSRAT, 8(3), 51-59.

Costa, L. B. M., \& Filho, M. G. (2016). Lean healthcare: review, classification and analysis of literature. Production Planning and Control, 27(10), 823-836.

Dea, Kurniasih, Subarnas, A., \& Djuhaeni, H. (2015). Peran Kepuasan Mutu Layanan Farmasi dalam Peningkatan Loyalitas Pasien di Rumah Sakit Al-Islam dan Santo Yusup Kota Bandung. Jurnal Farmasi Klinik Indonesia, 4(3), 206-217.

Fourie, C. J., \& Umeh, N. E. (2017). Application of Lean Tools in the Supply Chain of a Maintenance Environment. South African Journal of Industrial Engineering, 28(1), 176-189.

Galistiani, \& Satibi. (2013). Analisis faktor-faktor organizational capital: studi kasus instalasi farmasi rumah sakit di daerah istimewa Yogyakarta. Pharmacy, 10(1), 250-259.

Green, C. F., Crawford, V., Bresnen, G., \& Rowe, P. H. (2015). A waste walk through clinical pharmacy: How do the "seven wastes" of Lean techniques apply to the practice of clinical pharmacists. International Journal of Pharmacy Practice, 23(1), 21-26.

Hadi, K. (2003). Analisis Pengaruh Biaya Kualitas Terhadap Harga Pokok Penjualan Pada Industri Pemintalan Benang Di PT.Primayudha Mandirijaya. Universitas Diponegoro.

Hansen, D. R., \& Mowen, M. M. (2009). Akuntansi Manajerial. (D. Arnos, Ed.) (8 ed.). Jakarta: Salemba Empat.

Hapsari, S., Saputra, B., \& Rismadi, B. (2013). Evaluasi Efektivitas Pengendalian Biaya Produksi Dan Efisiensi Biaya Produksi (Studi Kasus Di PT. XYZ). Journal of Management Studies, 2(1), 38-60. 
Hasle, P., Nielsen, A. P., \& Edwards, K. (2016). Application of Lean Manufacturing in Hospitals - the Need to Consider Maturity, Complexity, and the Value Concept. Human Factors and Ergonomics in Manufacturing \& Service Industries, 26(4), 430-442.

Horngren, Charles, T., Srikant, M. D., \& Foster, G. (2008). Akuntansi Biaya. (D. Adhariani, Ed.) (11 ed.). Jakarta: Erlangga.

Martusa, H., Haslim, \& Henri, D. (2011). Peranan Analisis Biaya Kualitas dalam Meningkatkan Efisiensi Biaya Produksi (Studi Kasus pada PTP Nusantara VIII Kebun Ciater). Akurat Jurnal Ilmiah Akuntansi, 4(2), 1-20.

Modi, D. B., \& Thakkar, H. (2014). Lean Thinking: Reduction of Waste, Lead Time, Cost through Lean Manufacturing Tools and Technique. International Journal of Emerging Technologies and Advanced Engineering, 4(3), 339-344.

Pujotomo, D., \& Armanda, R. (2011). Penerapan Lean Manufacturing Untuk Mereduksi Waste Di Industri Skala UKM. J@TI Undip, VI(3), 137-146.

Radnor, Z. J., Holweg, M., \& Waring, J. (2012). Lean in healthcare: The unfilled promise? Social Science and Medicine, 74(3), 364-371.

Sayyida, G., Fahma, F., \& Iftadi, I. (2018). Process Improvement in Outpatient Installation RSUD dr. Soediran Mangun Sumarso Using Lean Hospital Approach. IOP Conference Series: Materials Science and Engineering, 319(1), 12077.

Sigalingging, E. A., Tama, I. P., \& Riawati, L. (2014). Penerapan Lean Manufacturing untuk Mereduksi Waste pada Produksi Filter Rokok dengan Wam dan Metode Taguchi (Studi Kasus Pada PT Essentra, Sidoarjo). Jurnal Rekayasa dan Manajemen Sistem Industri, 2(3), 495-505.

Siregar, \& Amalia. (2004). Farmasi rumah sakit: teori dan penerapan. Jakarta: Penerbit Buku Kedokteran EGC.

Sudradjat, D. S. (2016). Identifikasi Waste Pada Proses Produksi Kaca Gravier Menggunakan Metode Value Stream Analysis Tools (Valsat) Dan Usulan Perbaikan Menggunakan Diagram Fishbone Pada CV. Ria Glass. Universitas Airlangga.

Suharyono, M. W., \& Adisasmito, W. B. . (2006). Analisis Jumlah Kebutuhan Tenaga Pekarya Dengan Work Sampling Di Unit Layanan Gizi Pelayanan Kesehatan. Jurnal Manajemen Pelayanan Kesehatan, 9(2), 72-79.

Tandiontong, M., Sitanggang, F., \& Carolina, V. (2010). Pengaruh Biaya Kualitas terhadap Tingkat Profitabilitas Perusahaan (Studi Kasus pada The Majesty Hotel and Apartment, Bandung). Akurat Jurnal Kuliah Akuntansi, 2(1).

Wahyuningtias, K. A. (2013). Pengaruh Biaya Kualitas terhadap Produk Rusak pada CV. Ake Abadi. Jurnal EMBA, 1(3), 1-10. 